\author{
Raazia Moosa \\ Academic Support, \\ University of the Witwatersrand \\ Raazia.moosa@wits.ac.za \\ DOI: $h$ ttp://dx.doi. \\ org/10.18820/2519593X/pie. \\ v37i1.7 \\ ISSN 0258-2236 \\ e-ISSN 2519-593X \\ Perspectives in Education \\ 2019 37(1): 87-100
}

Date Published: February 2020

\section{Critical Attributes of Effective Classrooms: Insights from Classroom Engagement}

\begin{abstract}
Student success is an international priority and various initiatives have been implemented in higher education to improve success rates, especially in the first year of study. However, few of these initiatives have focused on the classroom context even though classroom engagement is a prerequisite for success. The purpose of this study was to ascertain what classroom surveys could reveal about student engagement. In addition, it aimed to advance the notion of engagement to include what students and lecturers do in the classroom to make classroom learning more effective. An exploratory case study research design was used, which drew on Tinto's (2012) attributes of effective classrooms as the theoretical framework. The major finding is that critical reflections on classroom engagement by lecturers and students can improve engagement in the classroom by focusing on the mismatches between students' and lecturers' perspectives and using these to improve classroom practices. The findings thus revealed the importance of reflective practice by both students and lecturers as an attribute of effective classrooms and in doing so have contributed to theory by adding reflective practice in teaching and learning to Tinto's (2012) attributes of effective classrooms. This article concludes with a discussion of the implications of this study for improving engagement in the classroom and ultimately student success.
\end{abstract}

Key words: student engagement, classroom surveys, attributes of effective classrooms, reflective practice, lecturer and student perceptions, classroom experience, classroom engagement

\section{Introduction}

Student success is an international priority and various initiatives have been implemented in higher education (HE) to improve success rates, especially in the first year of study. Student engagement represents one such initiative. Kift (2004) argues that factors such as massification and reduced funding have contributed to disengagement in $\mathrm{HE}$. In order to improve engagement, various universities internationally have opted to participate in student engagement surveys. These surveys were customised for the South African context by the University of the Free State and are used to assess how engaged students are at the institutional as well as at the course level. This study focuses specifically on engagement at the course level, rather than on students' engagement at the institutional level. Tinto (2012) maintains that few initiatives to improve 
student success have borne fruit because they have not focused on improving the classroom experience. As such, student engagement is increasingly being mooted as a prerequisite for learning (Pittaway, 2012), even though it is poorly conceptualised and defined in the literature (Baron \& Corbin, 2012). Little attention is paid to the classroom context although classroom engagement could be considered a prerequisite for success. The purpose of the present study was to ascertain what classroom surveys could reveal about the attributes of effective classrooms for student engagement and to advance the notion of engagement on the basis of what students as well as lecturers do in the classroom.

The central argument presented in this paper is that critical reflections on classroom engagement by lecturers and students can improve engagement in the classroom and bridge the gap between theory and practice by allowing lecturers to consider strategies to improve engagement. This study provides an aggregated view of lecturers' and students' perceptions of engagement in the classroom that could lead to effective classroom practices. The literature in the field of student engagement is highlighted before discussing engagement in the classroom. Tinto's (2012) attributes of effective classrooms are then used as a lens to view characteristics of engagement in the classroom. This is followed by an explanation of the methodology which is based on a qualitative exploratory case study design. The findings are then discussed using Tinto's attributes of effective classrooms. The contribution this study makes is that it will show that critical reflections by lecturers on student engagement surveys are able to highlight ways of improving student engagement and that student reflections can improve learning and provide lecturers with the feedback required to improve teaching and learning. This paper then concludes with implications for theory and practice.

\section{Student engagement}

The concept of engagement is a complex construct (Zepke et al., 2012; 2013; Zepke \& Leach, 2010) that includes the socio-cultural nature of lecturers' and students' experiences in the classroom (Bryson \& Hand, 2007). Student engagement in the classroom has been the focus of previous studies (Strydom \& Hen-Boisen, 2017; Zepke et al., 2014; Ainley, 2013; Bryson \& Hand, 2007). The term engagement means different things in different contexts. Researchers in the United Kingdom, see it as a qualitative perception of patterns of engagement, whereas those in the United States see it as quantifying variables of engagement (Bryson \& Hard, 2012). Using engagement as a means to investigate the possibilities of improving student learning, Bryson and Hand (2007) argue that student engagement occurs on a continuum from disengagement to engagement. Engagement is complex and therefore disengagement occurs. A student could thus be engaged in one course and be disengaged in another course or engaged in a course but not fully engaged in the university (Bryson \& Hand, 2007). In their study, Bryson and Hand (2007) found that engagement with module tasks revealed that "some students were engaged at the start of their higher education experience and retained this and others grew more engaged as they went on" (Bryson \& Hand, 2007: 359). Engagement is thus context specific with no universal definition despite various perspectives.

The manner in which students engage with learning is seen in terms of constructivist (Coates, 2005) and behaviourist perspectives (Strydom \& Hen-Boisen, 2017; Kahu, 2013; Zepke \& Leach, 2010; Kuh, 2009). On the one hand, the constructivist perspective stresses that "learning is influenced by how an individual participates in educationally purposeful activities" (Coates, 2005: 26). On the other hand, the behaviourist perspective emphasises student satisfaction and achievement and views student engagement as an evolving construct 
that focuses on institutional practices and student behaviours such as time on task, teaching practices, and social and academic integration (Strydom \& Hen-Boisen, 2017; Kahu, 2013; Kuh, 2009). Classroom surveys on student engagement are thus based on the behaviourist perspective since the aspects deemed important by this perspective are incorporated into the surveys. Kahu (2013) consequently argues that the behaviourist perspective on student engagement enjoys the most support. The student-institution relationship is reciprocal where institutions provide opportunities and conditions to learn and students are responsible for learning (Krause \& Coates, 2008). Kinzie points out that "engagement is simultaneously about students' investment in educational activities and also about the intentional structuring and facilitation of students' involvement in enriching learning experiences" (2010: 140). Student engagement is, however, only one indicator of student success. The behaviourist perspective assumes that engagement will lead to success if the right conditions prevail (Zepke \& Leach, 2010). Zepke and Leach (2010) therefore focus on how to improve student success in HE with the emphasis on retention, completion, and employability. Student engagement is thus recognised as a key factor in promoting learning, and studies on engagement have consequently focused on learning and achievement in HE (Zepke et al., 2014; Kahu, 2013).

\section{Classroom surveys on student engagement}

Classroom surveys have been used to measure student engagement at the micro-level in the classroom, and positive outcomes such as improved learning and interaction between lecturers and students, have been noted when students are engaged through active practices in the classroom (Bryson \& Hand, 2007). However, the massification of HE has often made engagement difficult, especially in the classroom (Bryson \& Hand, 2007), as there are fewer opportunities for students to articulate their expectations or obtain individual feedback on their assignments. Lecturers are also challenged by time constraints to engage with alternative pedagogies or attend professional development courses. Other challenges faced by lecturers include a diverse student body in terms of preparedness and demographics, large classes, and limited resources. Resource constraints in terms of funding for tutorials is also a reality. Although diversity is a reality in the classroom, Kift states that "the one thing that all students have in common in all their diversity is that they come to us to learn and it is as learners that students must be primarily engaged if they are to have a successful FYE" (2004: 3). Nevertheless, the transition from school to the social and academic demands of university life could be facilitated by enhancing classroom effectiveness through engagement (Tinto, 2012).

Studies on classroom engagement have been conducted internationally and, more recently, in South Africa. Internationally, Zepke et al. (2012) examined whether student engagement could be improved through research at the sub-institutional level (at the level of a course), rather than at the institutional level. Following the same line of inquiry, Thomas et al. (2015) questioned whether classroom surveys could improve student success or engagement by focusing on the course level rather than on the institutional level. Zepke et al. (2012) thus maintained that the best unit of study for student engagement is the "sub-institutional level such as courses" (329). Low expectations are associated with disengagement, and Kift (2004) states that disengagement is a reality of the classroom experience for some students. In another classroom study, Ainley (2012) found a relationship between engagement and interest in classroom activities that are likely to lead to students acquiring knowledge more readily. Zepke et al. (2014) also examined whether students and lecturers shared similar understandings of engagement in the classroom and found that the students and lecturers in 
their study had dissimilar as well as similar perceptions about what engages students in the classroom. Kift (2004) thus proposed curriculum renewal to enhance student engagement. In addition, Bryson and Hand (2007) maintained that students will engage if lecturers demand high standards and provide them with feedback. Lecturers' support for students will therefore impact positively on students' levels of engagement.

In the South African context, the South African Survey on Student Engagement (SASSE) is based on the American version and was customised for South Africa by the University of the Free State. It provides information at the institutional level whereas classroom surveys on student engagement (CLASSE) focus on the classroom level. The classroom surveys on student engagement include both a CLASSE (lecturer survey) and a CLASSE (student survey). These surveys provide insight into classroom engagement with the aim of developing effective educational practices. The ultimate aim of these surveys is to increase student success rates (Strydom \& Hen-Boisen, 2017). A study by Strydom and Hen-Boisen (2017) found that a large number of the students in their study memorised course material even though their lecturers did not consider memorisation desirable. The students stressed the importance of tutoring or teaching other students while the lecturers did not consider this important. Strydom and Hen-Boisen (2017) also found that preparation and participation in class were behaviours that lecturers believed students needed to improve on. This South African study thus showed similar trends to international studies even though the context differed and even though classroom surveys on engagement in South African have only recently been adopted.

Previous studies internationally and nationally focused on whether to improve engagement by focusing on the course level (Zepke et al. 2012), or whether classroom surveys could improve student success or engagement (Thomas et al., 2015). Another focus in the national literature (Strydom \& Hen-Boisen, 2017), has been on how student engagement surveys could provide evidence to inform student success. What these studies lack is a focus on how lecturers' and students' reflections on the student engagement data could inform effective classrooms. This is a gap in the literature which this study fills. Reflective practice is a dynamic concept (Cunningham 2001), with philosophical origins in constructivism. Learning is thus viewed as "an active process where learners reflect upon their current and past knowledge and experiences to generate new ideas and concepts" (2). Cunningham (2001) argues that reflective practice is a continuous cycle which involves self-evaluation and self-observation to understand actions and reactions and refine practices. Using classroom engagement surveys to ascertain what the reflective perceptions of lecturers and student are, could inform effective classrooms and fill a gap in the literature. The following section proposes a theoretical framework for examining effective classrooms in the South African context.

\section{Theoretical framework: Attributes of effective classrooms}

Tinto is a well-known scholar in the field of student success and engagement. The classroom attributes or characteristics of effective classrooms that he articulates are a result from his work in the field. Tinto (2012) highlights the importance of students' experiences in the classroom by focusing on the attributes of effective classrooms and argues that improving classroom experience will lead to greater student success. These attributes of effective classrooms were chosen as a theoretical framework because they have not been explored in the South African context. They also focus on the classroom situation and have direct bearing on engagement in the classroom. Tinto's (2012) attributes form the basis of effective classrooms and focus 
on "clear expectations, timely support, assessment and feedback, engaging pedagogies and enhancing teaching skills" (4-7), which inform and serve as data points to give an indication of engagement in the classroom. These attributes will thus be used as a theoretical framework to guide the analysis of the data, in this study.

A focus on these attributes indicates that the expectations that lecturers have of their students, as well as the expectations that students have of themselves, influence performance in a course. Tinto argues that "student success is directly influenced not only by the clarity and consistency of expectations, but also by their level" (2012: 4), with high expectations therefore fostering student success. Students' behaviour can then be shaped accordingly, based on their perceptions of the lecturer's expectations both verbally and in writing. Timeous support underpins high expectations, especially in the first year of study. However, this support must be contextualised in terms of the demands placed on students in the classroom (Tinto, 2012) in order for it to impact on student success. According to Tinto (2012), continuous assessment of and feedback on students' performance should be structured in a way that allows students to modify their behaviour. Tinto (2012) adds that as engagement is the most salient attribute of an effective classroom, both academic and social learning with lecturers and peers in classroom activities are more likely to increase the chances of classroom success. Engagement in the learning process will thus occur through learning activities, and students are also likely to gain social and emotional support through social affiliations in the classroom, which can ultimately foster success in the classroom (Tinto, 2012; Ainley, 2012; Bryson \& Hand, 2007).

Learning activities lay the foundation for engaging pedagogies as an attribute of effective classrooms, and various assessment methods are available to assess learning. Lecturers can also contribute by enhancing their teaching competence. Tinto (2012) argues that the skills of teaching staff are vital for the implementation of pedagogies of engagement. Most lecturers in HE have not developed appropriate practices in curriculum development, pedagogy, and assessment, which would increase their effectiveness in the classroom and consequently promote student engagement and success (Tinto, 2012). Tinto (2012) highlights recent initiatives aimed at encouraging new staff members to attend short courses and degree programmes to improve their teaching. How these courses are conceptualised and whether they are voluntary will largely determine their effectiveness (Tinto, 2012). However, their impact will be limited as there are generally more existing staff in the HE system than new staff. Nevertheless, professional development is a worthy initiative to promote student engagement in the classroom. These attributes are thus essential for effective classrooms but whether they are sufficient and relevant to the South African context will become evident through the data analysis process.

\section{Methodology}

The present study was based on a qualitative, exploratory case study research design. According to Creswell (2012: 465), a case study is "an in-depth exploration of a bounded system". High-risk courses represented the bounded system or the 'case'. This study is described as an exploratory case study because it was the first time that classroom surveys on student engagement had been conducted at a research intensive university in South Africa as part of a pilot project that began in 2015. Three data collection methods were employed to explore the perceptions of lecturers and students on effective engagement in classrooms. These methods included interviews with the lecturers, a review of the reports based on a 
quantitative analysis of classroom surveys with the lecturers and the students, and a review of institutional data on high-risk courses. The data were aggregated across four faculties (Commerce, Law and Management; Engineering and the Built Environment; Humanities and Science). The aim of this study was to ascertain whether the data generated from classroom surveys could be used to improve student engagement and ultimately student success by focusing on the attributes of a micro-level component of an institution such as the classroom. The research question posed is to what extent, if any, could classroom surveys improve engagement in the classroom and contribute to the characteristics of effective classrooms.

A purposive sampling strategy was used. The sample was drawn from classroom surveys on student engagement conducted in 2015 in 25 high-risk courses identified through the University's early warning system. A high-risk course was defined as a course with a pass rate of $66 \%$ or lower. Within the 25 courses, 1945 students completed the questionnaires, and 18 lecturers agreed to participate in the surveys. Of the 18 lecturers, nine interviews were conducted with lecturers who were available and still employed at the University. The 18 courses were mostly first-year courses or courses offered for the first time in the second year of study. Krause and Coates (2008) stress the importance of qualitative and quantitative measures in engagement surveys and propose a synthesis of qualitative and quantitative data. This was achieved by analysing reports based on quantitative methods and combining them with qualitative interviews and an analysis of course pass rates. The interviews were conducted between 2015 and 2016, transcribed verbatim, and analysed using content analysis. A limitation of this study was that the courses were not representative of all the highrisk courses at the University. In addition, a qualitative case study was used, which prevented any generalisation of the findings. Furthermore, the results were aggregated, and an in-depth view of a particular course is possible only through a disaggregated approach, which is not presented in this article.

\section{Findings}

The findings are based on an analysis of the reports on the classroom surveys completed by lecturers and students, as well as interviews conducted with lecturers. An aggregated view is presented to give an overall picture of classroom engagement. The analysis of data drew on Tinto's (2012) attributes of effective classrooms.

\section{Expectation of learning activities}

The analysis of the data indicated that lecturers and the students had different expectations of the same course with regard to preparation for the class, the time spent on tasks, and the ability to combine ideas from different subjects or to discuss ideas with others. Most lecturers and students considered it important to attend class and to take notes in class. Most of the students did not consider the need to work hard as important nor did they consider it important to spend more than one hour on an assignment or to attend class prepared. Some students also did not consider it important to receive challenging content, to combine ideas from different subjects, or to discuss ideas with others. The lecturers however, considered these matters as an important indication of the students' commitment to engage in learning activities. Lecturers also expected students to come to class prepared. One lecturer stated an expectation of students as:

"So I wouldn't expect them to spend more than 3 hours ... I think the way I said it is, sit down for one hour a day before class and go through the lecture notes. Yes revising to reconcile what you 
have learnt to what you have pre-read, to what you would require ... do all the tuts and get done with that" (Lecturer 5).

Irrespective of the number of years a lecturer had taught, some lecturers indicated that it was essential to clarify important aspects of the course for students to enhance their engagement. Lecturers also reported that assumed knowledge and the importance of peer discussions and preparation for class, should not be taken for granted. While most lecturers perceived the need to work hard as important, one lecturer reported that the need to work hard or not might be a perception related to having some previous knowledge of the content. Previous knowledge of a course led some of the students to believe that they did not have to work as hard as students who were being exposed to the content for the first time. Nevertheless, expectations of learning activities highlighted a mismatch between the expectations of some lecturers and some students with an acknowledgement by both that some expectations could be legitimate.

\section{Inclusive academic support}

A specific question on inclusive support was not asked in the classroom surveys or in the interviews. This theme emerged during the analysis process. Lecturers highlighted the need for appropriate early interventions for students preferably after the first assessment. This was highlighted despite the large class sizes in excess of 200 students in the first year. Lecturers reported that support was provided in many courses not only by the lecturer but by tutors as well. The role of tutors was thus considered essential for engagement in the classroom. Lecturers also stressed the need for all students to receive extra support - not only those at risk of failing or those who required the extra support. In some courses, the stronger students who were obtaining first class passes, tended to take advantage of the additional academic support provided. Most lecturers indicated that additional academic support tutorials were small, consisting of between 10 and 15 students. One lecturer captured this as:

"We try and keep students at 10 or less working with a tutor and it's an opportunity for them to bring a draft, to answer a question or the introductory paragraph or whatever ... it's interesting because the strongest students are the ones who attend most often. This is intended for students who need help, but in fact the strongest keep getting stronger. So our remedial opportunity is being attended by some of our students who are getting first class marks, which you know is just one of those weird things that students do" (Lecturer 3).

The inclusive support recommended by lecturers, encompassed early interventions for students as well as inclusive tutorial support targeting all students. The surveys did not probe whether the students attended additional academic support tutorials, although such tutorials were mentioned by the lecturers as a common support mechanism implemented as part of the tutorial system. The findings thus indicated that tutorials are spaces for student engagement.

\section{Forms and frequency of assessment and feedback}

Some students reported that challenging assessment tasks were set, which required them to do their best. However, most students reported that it was not important to receive prompt oral or written feedback from the lecturer on their academic performance (e.g. marks from tests, exams, and assignments). Students also did not consider discussions with lecturers, on their assignment grades or detailed information about learning outcomes, as important. This is interesting as assessments are usually considered very important in shaping student learning. One lecturer's explanation for this related to the intake of stronger students with grades 
above $70 \%$ for mathematics and to the fact that the results were published on the learning management system, which mitigated against the collection of assignments and consultations with lecturers. In addition, most of the students reported that they did not discuss ideas with the lecturer outside the classroom and also that they did not consider it important to ask questions in the classroom. In sharp contrast, the lecturers believed that feedback on assessments was crucial because students could use it as a learning opportunity to improve on the next assessment. Most of the lecturers reported that opportunities to reflect on feedback were provided in some courses, however one lecturer noted that the students did not perceive feedback as a "major teachable moment". Lecturers also reported that emails from students and consultations with students increased close to exams, perhaps indicating that some students are marks driven with their focus on passing rather than learning. The mismatch between lecturers and students regarding the importance and frequency of feedback and consultations was raised by some lecturers. Continuous feedback from lecturers was built into tutorial preparation for assignments in some courses, and asking questions inside and outside the classroom was considered very important by most lecturers. Comments on assessment and feedback were exemplified as:

"... so what happens is that when we mark something, we got the feedback and we've got the mark. And they just really want to see the mark. But the problem with that is, let's say you got $60 \%$. Unless you have seen the comments that I have written on your assignment, how do you know where the problem is. I think often students just want a solution...I think feedback is important otherwise I wouldn't give you an assessment if I didn't think it was important" (Lecturer 8).

\section{Lecturer and peer engagement/affiliations}

Some students indicated that they enjoyed working with peers in group work sessions. However, the majority of students did not perceive working with classmates on projects and assignments during class or working with classmates outside of class to prepare assignments, as important. They also did not perceive as important the need to explain subject content to other students or to use emails and/or SMSs to communicate with the lecturer. In addition, some students did not consider it important to communicate with the lecturer to discuss assignments. In support of this, a lecturer in the Faculty of Science agreed with the students that communication with other students and the lecturer was not important. Most lecturers were in favour of consultation times and reported that they communicated these times to the students and also made their email addresses available to the students in the course outlines. A mismatch was noted with some lecturers who believed that lecturer and peer engagement or affiliations were very important. As such, lecturers and tutors as well as structured and intentional peer engagement was emphasised as important by some lecturers. Lecturers suggested capitalising on and incorporating students' perceived need to tutor each other into classroom pedagogy. The importance of peer engagement and discussion was also stressed by some lecturers. One lecturer noted that peer engagement was supported in the literature thereby confirming its importance. An example of a comment included:

"so it's not just one or two who ... feel that way [that they can explain the subject content to other students].... I can use that quite a lot then. But, I can even get them in a tut to tutor each others" (Lecturer 7). 
Lecturer and peer engagement was thus reported as important in a classroom situation where students engaged with one another. It is thus evident that a culture of teaching and learning that supports lecturer and peer engagement is essential for effective classrooms.

Classroom context (curriculum and engaging pedagogies)

curriculum

Lecturers and students used the term curriculum to refer to the content, discussions and assessments of their courses. Students and lecturers differed on their view of the importance of curriculum as a form of engagement. Students reported making limited contributions in class discussions and asking questions. This included limited inclusion of different viewpoints in class discussions or papers. Students added that they often attended class without having completed readings or assignments although the lecturers considered drawing on different viewpoints and preparation for class as key to success. Some students reported finding it difficult to follow the lecturer, and one lecturer raised this as a concern related to engagement in the classroom. How the students experienced learning as well as the curriculum was important for some lecturers. Some students also indicated that making judgements and synthesising and analysing data was important to them. Scaffolding and the avoidance of surface learning was highlighted as important by those lecturers who were interviewed. Some lecturers mentioned the challenges involved in getting students to prepare for class and added that deep learning on the part of students was an expectation of theirs. How the curriculum content was paced and scaffolded to foster engagement in the classroom was considered by lecturers to be important for students to achieve higher order learning in terms of Bloom's revised taxonomy. A reflection included:

"it's the higher order learning skills ... because they doing surface learning ... all of the things we find critical are all these deep level kind of applying. This is on that taxonomy all the higher order stuff ... so they recognise that this is what we want them to do, but they can't make those connections. So how do we synthesize if you haven't done the readings" (Lecturer 9).

\section{engaging pedagogies}

Engaging pedagogies such as working with classmates or using an electronic medium were not considered important by students in some courses, thus highlighting a mismatch between some lecturers' views on the importance of engaging pedagogies and those of some students. An analysis of the interviews with the lecturers revealed that engaging pedagogies employed in the classroom included the use of clickers, tutorials, pop-quizzes, consultation with lecturers, review sessions, peer support and group work, weekly concept tutorials, and reading and writing programmes. Some lecturers and students mentioned the importance of attending review sessions. In addition, some lecturers reported using engaging pedagogies to encourage active engagement and discussion as well as active peer learning. This was typified as:

"I use clickers and make them discuss among themselves in classes. I tell them to think about it and discuss it with somebody... just so there's active engagement and discussion and also active peer learning." (Lecturer 7).

"yeah I mean tutoring is something that I found, ...it makes a big difference." (Lecturer 4).

Engaging pedagogies were thus highlighted as a means of achieving higher order thinking skill and peer learning in the classroom. 


\title{
Reflective practice in teaching and learning
}

Reflections on teaching and learning practices were implicit in the classroom engagement surveys and interviews, but emerged during the analysis process. Completing these surveys enabled reflections on various issues such as expectations of learning activities, support, lecture and peer engagement, the curriculum, and engaging pedagogies. The classroom surveys enabled lecturers and students to reflect on engagement indicators. Lecturers' reflections included thinking about what pedagogic practices were good and why they were used, making the course expectations clearer to students on a weekly basis, and using feedback from the classroom engagement surveys to inform planning. Some reflective comments included:

"Hmm, so I need to make it more explicit" (Lecturer 7).

"so maybe, I need to start thinking outside the box and say next week, I'm going to do a pop quiz that has a potential prize, to see if they have read for the lecture" (Lecturer 5).

Reflections on the mismatch of expectations between students and lecturers were perceived by most of the lecturers as useful for improving classroom engagement. The majority of the lecturers also reported that reflective practice helped highlight mismatches between lecturer and student perceptions of teaching and learning and provided insights into who the students sitting in the classroom actually were and how best to improve engagement.

\section{Professional development}

Analysis of the interviews with the lecturers indicated that some lecturers were actively involved in improving their professional skills through conference attendance, registering for postgraduate diplomas in $\mathrm{HE}$, attending short courses, and various other activities to improve their teaching such as reading in the field of teaching and learning and attending internal university symposia. While obtaining a $\mathrm{PhD}$ was noted as a means of improving professional competence, one lecturer said it was a challenge as well. The comment was made that a lack of publications was not an indication that research in a discipline was not taking place and that attending teaching and learning conferences was essential for professional development. This was typified as:

\begin{abstract}
"so I will do a lot of reading and find out a lot of things about my field but l'm not writing papers about it. It doesn't mean that I'm not researching ...people need to be on top of their field and that's fine, but I see that [attending teaching and learning conferences] as important. It's not the same as me churning out papers about the research that I have done, it's improving my teaching" (Lecturer 8).
\end{abstract}

Engagement in the classroom thus included aspects of professional development and highlighted the importance of the partnership between lecturers and students in fostering student success.

\section{Discussion}

Tinto's (2012) attributes of effective classrooms served as a theoretical framework to guide the analysis of the data. The findings indicated that classroom surveys provide insight into how engagement in the classroom leads to effective classrooms. Reflective practices by lecturers and students emerged from this study and can be added as an attribute of effective classrooms. Congruence as well as mismatches between the lecturers' and students' perceptions of engagement in the classroom were evident. Similarities were highlighted 
between some lecturers and students who considered it important to attend class, to work with peers, to attend review sessions, to take notes in class, and to discuss ideas with others. Some comments indicated that students were required to make judgements, synthesise and analyse data and also that challenging assessment tasks encouraged students to do their best. Mismatches were noted between the lecturers' and the students' expectations of a course, what constituted engagement, the importance and frequency of feedback, the importance of peer and lecturer interaction, and the perception of how many hours of work was required. As is the case with the studies by Zepke et al. (2012) and Zepke (2013), classroom engagement surveys can be used as a strategy to enhance the experience of first-year students. However, these mismatches need to be addressed.

Zepke et al. (2010) argue that teaching has the greatest influence on engagement, a view supported by Bryson and Hand (2007), who state that lecturers should demand high standards, challenge students, make themselves freely available to discuss academic progress, and create inviting learning environments. The present study indicated that although the lecturers acknowledged the importance of consultation times and timeous feedback to students, a mismatch was evident between the importance that the students and the lecturers attached to such learning environments. Radloff and Coates (2010) found that students who engaged in higher forms of learning such as analysing, synthesising, and evaluating information, tended to be the most engaged, as was found also by Hockings et al. (2008) in their study. However, the findings in the present study indicated a mismatch between the students' and the lecturers' perceptions regarding the expectations of higher forms of learning. Higher order learning, analysing and synthesising material, together with diverse views in a course, were regarded by the lecturers as important and conducive to engagement, but this perspective was not shared by some students in this study. Kuh et al. (2005) found that high expectations of students and challenging assessment tasks enhanced engagement, provided that prompt and clear feedback was given.

The present study revealed that some students did not value challenging content or prompt assessment. In some cases, the assessments were not even collected, and the lecturers were not approached to obtain feedback. This is surprising since the students could have used the lecturers' feedback as a learning opportunity to do better in future assignments. Although some lecturers commented that their feedback was structured as proposed by Tinto (2012), students were not able to modify their behaviour. This study also provides an indication of student learning processes and how Bloom's taxonomy could be used to counter the mismatch between the students' and the lecturers' perceptions, thereby promoting engagement in the classroom. While these classroom insights are valuable, it should be noted that learning is not confined to the classroom and that the classroom is only one space where engagement to promote learning takes place.

\section{Implications and Concluding Remarks}

This study has implications for both theory and practice with regard to classroom surveys and their contribution to effective classrooms. The findings indicated that data from classroom surveys provides a means for lecturers and student to critically reflect on ways to improve engagement. Student reflections on engagement further provide lecturers with the feedback required to improve teaching and learning. Active reflection by lecturers is able bridge the gap between theory and practice by helping lecturers consider strategies to promote student engagement in the classroom. This study has contributed to theory by adding reflective practice in teaching and learning to Tinto's (2012) attributes of effective classrooms (see Figure 1). 


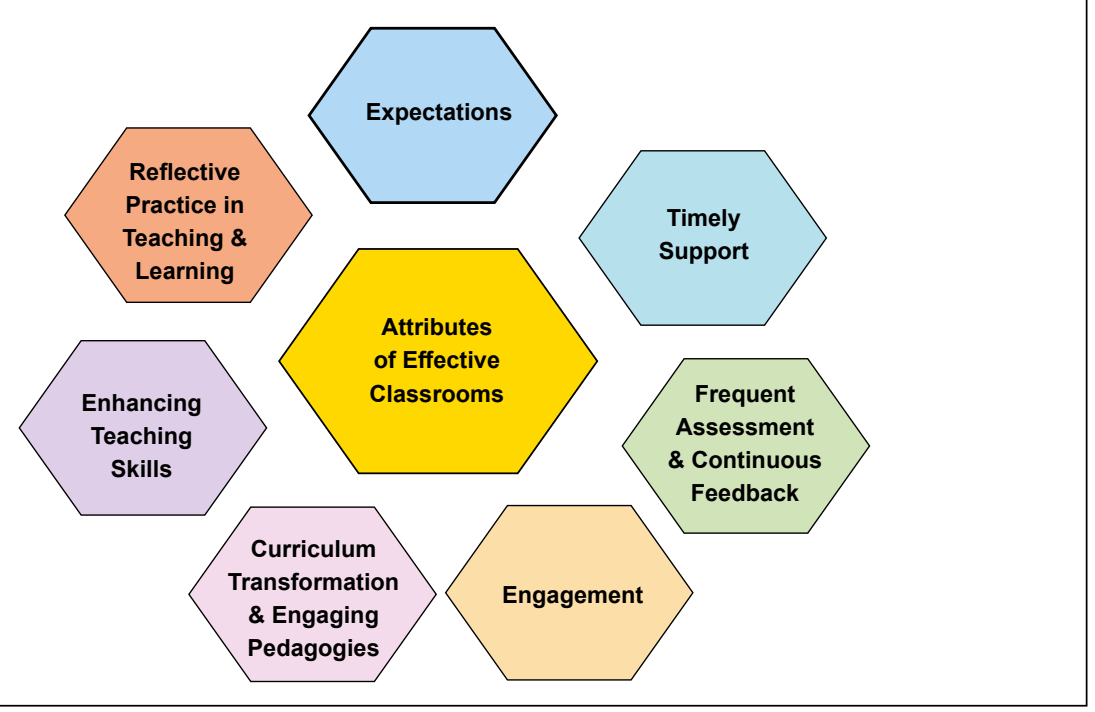

Figure 1 Attributes of effective classrooms (adapted from Tinto, 2012)

Within the South African context, this study highlighted areas for improvement in the curriculum and pedagogical practices based on classroom perceptions and mismatches between lecturers and students on what constitutes engagement. Another implication of this study is that valuable insights can be gained from research that focuses on the results of classroom surveys at the micro or sub-institutional level. If lecturers engage with and critically reflect on student engagement data and the mismatch between students' and lecturers' responses and more importantly, if this feeds into improving classroom practices, then there is value in administering the CLASSE surveys. Further implications are that high impact practices such as classroom engagement surveys can be linked to deep learning, which is also supported by the literature (Strydom \& Hen-Boisen, 2017; Kuh, 2013; 2005). However, why students engage in one course and engage less or do not engage in another course warrants further exploration. Future research could triangulate classroom surveys on engagement with other institutional surveys to improve the first-year experience as well as student success more broadly. Triangulation with other surveys could thus offer lecturers a more holistic view of engagement and effective classrooms. Through the reflective perceptions of lecturers and students, this study has shown that classroom surveys are able to improve engagement in the classroom despite some mismatches in perceptions and that reflective practice through engagement is an attribute of effective classrooms.

\section{Reference List}

Ainley, M. 2012. Students' interest and engagement in classroom activities. In: S.L. Christenson et al. (Eds.), Handbook of Research on Student Engagement, Springer Science \& Business Media, LLC. https://doi.org/10.1007/978-1-4614-2018-7_13

Baron, P. \& Corbin, L. 2012. Student engagement: Rhetoric and reality. Higher Education Research \& Development, 31(6), 759-772. https://doi.org/10.1080/07294360.2012.655711 
Bryson, C. \& Hand, L. 2007. The role of engagement in inspiring teaching and learning. Innovations in education and teaching international, 44(4), 349-362. https://doi. org/10.1080/14703290701602748

Coates, H. 2005. The value of student engagement for higher education quality assurance, Quality in Higher Education, 11(1), 25-36. https://doi.org/10.1080/13538320500074915

Creswell, J.W. 2012. Educational research: Planning, conducting, and evaluating quantitative and qualitative research (4th Ed.). Boston: Pearson.

Cunningham, F.M.A. 2001. Reflective teaching practice in adult ESL Settings. Eric Digest, 1-7.

Hockings, C. Cooke, S. Yamashita, H. McGinty, S., \& Bowl, M. 2008. Switched off? A study of disengagement among computing students at two universities. Research Papers in Education, 23(2), 191-201. https://doi.org/10.1080/02671520802048729

Kahu, E.R. 2013. Framing student engagement in higher education. Studies in Higher Education, 38(5), 758-773. https://doi.org/10.1080/03075079.2011.598505

Kift, S. 2004. Organising first year engagement around learning: Formal and informal curriculum intervention. In: 8th Pacific Rim First Year in Higher Education Conference, Dealing with Diversity, Queensland University of Technology in conjunction with Monash University, Melbourne, Australia.

Kinzie, J. 2010. Student engagement and learning: Experiences that matter. Taking Stock: Research on Teaching and Learning in Higher Education, 139-154.

Krause, K.L. \& Coates, H. 2008. Students' engagement in first-year university. Assessment \& Evaluation in Higher Education, 33(5), 493-505. https://doi.org/10.1080/02602930701698892

Kuh, G.D. 2013. What matters to student success: The promise of high-impact practices. NMHEAR Conference. Albuquerque NM February 28, 2013. National Institute for Learning Outcomes Assessment. Making Learning Outcomes Usable \& Transparent. Indiana University Center for Postsecondary Research.

Kuh, G.D. 2009. The national survey of student engagement: Conceptual and empirical foundations. New directions for institutional research, 2009(141), 5-20. https://doi.org/10.1002/ ir.283

Pittaway, S.M. 2012. Student and staff engagement: Developing an engagement framework in a Faculty of Education. Australian Journal of Teacher Education, 37(4), 37-45. https://doi. org/10.14221/ajte.2012v37n4.8

Radloff, A. \& Coates, H. 2010. Doing more for learning: Enhancing engagement and outcomes. Australasian student engagement report. Camberwell, Victoria: Australian Council for Educational Research.

Strydom, F. \& Hen-Boisen, L. 2017. Using engagement data for change and empowerment at course level. In: F. Strydom, G.D. Kuh, \& S. Loots (Eds.), Engaging students: Using evidence to promote student success. Bloemfontein: Sun Media, 205-218.

Tinto, V. 2012. Enhancing student success: Taking the classroom success seriously. The International Journal of the First Year in Higher Education, 3(1), 1. https://doi.org/10.5204/ intjfyhe.v3i1.119 
Thomas, N.J., Brown, E.A., \& Thomas, L.Y. 2015. Use of student response and engagement systems in the collegiate classroom: An educational resources review. Journal of Hospitality, Leisure, Sport \& Tourism Education, 17, 59-61. https://doi.org/10.1016/j.jhlste.2015.09.002

Zepke, N., Leach, L., \& Butler, P. 2014. Student engagement: students' and teachers' perceptions. Higher Education Research \& Development, 33(2), 386-398. https://doi.org/10 $.1080 / 07294360.2013 .832160$

Zepke, N. 2013. Student engagement: A complex business supporting the first year experience in tertiary education. The International Journal of the First Year in Higher Education, 4(2), 1. https://doi.org/10.5204/intjfyhe.v4i2.183

Zepke, N., Butler, P., \& Leach, L. 2012. Institutional research and improving the quality of student engagement. Quality in Higher Education, 18(3), 329-347. https://doi.org/10.1080/13 538322.2012.730338

Zepke, N. \& Leach, L. 2010. Improving student engagement: Ten proposals for action. Active Learning in Higher Education, 11(3), 167-177. https://doi.org/10.1177/1469787410379680 